\title{
ANALISIS PENYESUAIAN TARIF DASAR PADA PERUSAHAAN DAERAH AIR MINUM (PDAM) DI KABUPATEN LAMONGAN
}

\author{
*(Henny Mahmudah \\ Prodi Manajemen, Fakultas Ekonomi, Universitas Islam Lamongan \\ Jl. Veteran No.53A Lamongan \\ Telp. ( 0322 ) 324706, Faks. ( 0322 ) 324706 \\ Email:jpim.unisla@gmail.com
}

\begin{abstract}
ABSTRAK
Penelitan ini bertujuan untuk mengetahui kebijakan tarif yang diberlakukan oleh perusahaan daerah air minum (PDAM) Lamongan. Untuk mengetahui cara penentuan harga pokok produksi di perusahaan daaerah air minum (PDAM) Lamongan. Metode analisis data yang digunakan yaitu: Full Cost Recovery adalah Metode pemulihan biaya secara penuh (cost recovery method), dan menggunakan penentuan Harga Pokok Penjualan (HPP), BT= Biaya Total, BL= Biaya Langsung, BTL= Biaya Tidak Langsung. Hasil penelitian yang diperoleh dari kebijakan tarif yaitu sesuai Peraturan Menteri dalam Negeri nomor 23 tahun 2006 bahwa tarif dasar pada tahun 2014 sebesar $2500 \mathrm{M}^{3}$,mengalami kerugian dengan Cara Penentuan Harga Pokok Produksi (HPP). Metode penentuan harga pokok produksi dengan memperhitungkan seluruh biaya produksi, dengan hasil HPP pada tahun 2012 sebesar: 2.765, tahun 2013 sebesar: 2.969, tahun 2014 sebesar: 3.777 Dari hasil analisis disimpulkan bahwa Penyesuaian Tarif PDAM Kabupaten Lamongan 2014 terhadap Peraturan Menteri Dalam Negeri nomor 23 Tahun 2006. cara penentuan harga pokok produksi yang dilakukan oleh PDAM Kabupaten Lamongan dengan menggunakan metode dalam penyusunan HPP adalah dengan menggunakan metode full costing. Metode Full costing merupakan metode penentuan harga pokok produksi dengan memperhitungkan seluruh biaya produksi.
\end{abstract}

Kata Kunci : Penyesuaian Tarif Dasar (PDAM)

\section{PENDAHULUAN}

Perusahaan Daerah minum air adalah suatu kesatuan produksi yang bersifat memberi jasa, menyelenggarakan kemanfaatan umum dan memupuk pendapatan. Menurut Fauzi (2004:320) Air memiliki fungsi strategis bagi kehidupan manusia yaitu fungsi sosial, fungsi ekologi dan fungsi ekonomi.
Tarif Air Minum Menurut McCarthy dan Perreault (2009:79), Tarif Air Minum merupakan jasa pelayanan air minum yang wajib dibayarkan oleh pelanggan untuk setiap pemakaian air minum yang diberikan oleh perusahaan atau penyelenggara. 
Tarif Air Minum Menurut McCarthy dan Perreault (2009:79), Tarif Air Minum merupakan jasa pelayanan air minum yang wajib dibayarkan oleh pelanggan untuk setiap pemakaian air minum yang diberikan oleh perusahaan atau penyelenggara. Penyesuaian tarif yang diberlakukan oleh PDAM Lamongan adalah dengan cara diskriminasi harga antar antar golongan masyarakat dan konsep increasing block tariff untuk tiap tingkatan blok pemakaian air bersih. Diskriminasi harga ditujukan agar tercipta subsidi silang (cross subsidies) dari masyarakat berpendapatan tinggi ke masyarakat berpendapatan rendah, sedangkan konsep increasing block tariff bertujuan untuk mengerem konsumsi air bersih oleh pelanggan dikarenakan harga yang semakin tinggi untuk setiap peningkatan konsumsi air bersih.

Rumusan masalah pada penelitian ini adalah 1) Bagaimana kebijakan tarif yang diberlakukan oleh perusahaan daerah air minum (PDAM) Lamongan? 2)Bagaimana cara penentuan harga pokok produksi di perusahaan daerah air minum (PDAM) Lamongan?

Pengertian Tarif Air Minum Menurut McCarthy dan Perreault (2009:79), Tarif Air Minum merupakan jasa pelayanan air minum yang wajib dibayarkan oleh pelanggan untuk setiap pemakaian air minum yang diberikan oleh perusahaan atau penyelenggara.

Pengertian Tarif sering kali diartikan sebagai daftar harga (sewa, ongkos dan sebagainya) sehingga dari pengertian tersebut dapat disimpulkan bahwa tarif sama dengan harga. Tarif adalah salah satu instrumen dari kebijakan perdagangan luar negeri yang membatasi arus perdagangan internasional. Dari pendapat-pendapat diatas maka dapat ditarik kesimpulan bahwa tarif merupakan pungutan yang dibebankan untuk semua barang-barang yang melewati batas negara baik untuk barang yang masuk maupun keluar. Jenis-Jenis Tarif Dalam penghitungan tarif air minum, tarif dikelompokan terhadap 3 macam pengelompokan (a) Tarif rendah yakni tarif yang bersubsidi yang nilainya lebih kecil dari biaya dasar. (b) Tarif dasar yakni tarif yang sama dengan biaya dasar dan dengan kata lain tarif dasar adalah equivalent dengan biaya besar. (c) Tarif penuh yakni tarif yang nilainya lebih besar dari biaya dasar. (d) Tarif kesepakatan yakni nilainya berdasarkan kesepakatan antara PDAM dengan pelanggan.

\section{LANDASAN TEORI}

Penentuan Tarif Menurut McCarthy dan Perreault (2009: 352), dalam Tarif merupakan harga atau nilai sesuatu yang telah diperhitungkan dan ditetapkan yang harus dibayarkan oleh konsumen dengan nilai uang tertentu untuk mendapatkan suatu komoditi yaitu berupa barang atau jasa. (a) Penetapan Tarif Dalam Permadgi, Penetapan Tarif air oleh PDAM diatur dalam Peraturan Menteri Dalam Negeri No 23 tahun 2006 tentang Pedoman Teknis dan Tata Cara Pengaturan Tarif Air Minum pada Perusahaan Daerah Air MInum (PDAM). Pasal 3: (1) Tarif untuk Standar kebutuhan pokok air minum harus terjangkau oleh daya beli masyarakat pelanggan yang berpenghasilan sama dengan Upah Minimum Provinsi. (2) Tarif memenuhi prinsip keterjangkauan Sebagaimana dimaksud pada ayat (1) apabila pengeluaran rumah tangga untuk memenuhi standar kebutuhan pokok air minum tidak melampaui $4 \%$ (empat 
perseratus) dari pendapatan masyarakat pelanggan. 3) Keadilan dalam pengenaan tarif Dicapai melalui penerapan tarif diferensiasi dengan subsidi silang antar kelompok pelanggan.

Pasal 4: Tarif ditetapkan dengan mempertimbangkan keseimbangan dengan tingkat mutu pelayanan yang diterima oleh pelanggan. Pasal 7: (1) Proses perhitungan dan penetapan tarif harus dilakukan secara transparan dan akuntabel. (2) Proses perhitungan dan penetapan tarif yang transparan sebagaimana dimaksud pada ayat (1) dilakukan PDAM dengan (a) Menyampaikan secara jelas informasi yang berkaitan dengan perhitungan dan penetapan tarif kepada para pemangku kepentingan (b).Menjaring secara bersungguh-sungguh aspirasi yang berkaitan dengan perhitungan dan penetapan tarif dari para pemangku kepentingan. (3) Proses perhitungan dan penetapan tarif yang akuntabel Sebagaimana dimaksud pada ayat (1) harus menggunakan landasan perhitungan yang mudah dipahami dan dapat dipertanggung jawabkan kepada para pemangku kepentingan.

Pasal 17: (1) Tarif dibedakan dalam 4 (empat) jenis, (a) tarif rendah sebagaimana dimaksud pada ayat (1) huruf a, nilainya Iebih rendah dibanding biaya dasar.

b. tarif dasar sebagaimana dimaksud pada ayat (1) huruf $b$, nilainya sama atau ekuivalen dengan biaya dasar. b) tarif penuh sebagaimana dimaksud pada ayat (1) huruf c, nilainya Iebih tinggi disbanding biaya dasar. c) tarif kesepakatan sebagaimana dimaksud pada ayat (1) huruf d, nilainya berdasarkan kesepakatan antara PDAM dengan pelanggan.
Adapun tujuan dari penelitian ini adalah Untuk mengetahui kebijakan tarif yang diberlakukan oleh perusahaan daerah air minum (PDAM) Lamongan. Untuk mengetahui cara penentuan harga pokok produksi di perusahaan daaerah air minum (PDAM) Lamongan.

\section{METODELOGI PENELITIAN}

Jenis penelitian yang digunakan oleh penulis adalah Metode Deskriptif Kuantitatif, Metode penelitian kuantitatif yaitu sebagai metode penelitian yang berlandaskan pada filsafat positivisme, digunakan untuk meneliti pada populasi atau sampel tertentu, teknik pengambilan sampel pada umumnya dilakukan secara random, pengumpulan data menggunakan instrumen penelitian, analisis data bersifat kuantitatif atau statistik dengan tujuan untuk menguji hipotesis yang telah ditetapkan Sugiyono (2014:14).

Analisis Deskriptif digunakan agar penelitian tidak hanya terbatas pada data statistik yang bersifat kaku, selain itu agar penelitian dapat menghasilkan kesimpulan yang lebih menarik. Pada penelitian ini, analisis deskriptif digunakan untuk membuat gambaran secara sistematis mengenai karakteristik pola pemanfaatan dan pengelolaan sumberdaya air dalam rangka pemenuhan air bersih bagi masyarakat.

Tehnik Penarikan Sampel (1) Populasi menurut suharsmi arikunto (2010:173) adalah keseluruhan subyek penelitian. Apabila seseorang ingin meneliti sesuai elemen yang ada dalam wilayah penelitian, maka penelitiannya merupakan penelitian populasi. Studi atau penilaiannya juga disebut studi populasi atau studi sensus. Yang menjadi Populasi dari penelitian ini 
yang diambil yaitu data penyesuaian tarif yang ada pada perusahaan daerah air minum (PDAM) Lamongan. 2). Sampel Sedangkan Sampel Menurut Suharsmi Arikunto (2010:174) adalah sebagaian atau wakil populasi yang diteliti. Bila populasi besar, dan peneliti tidak mungkin mempelajari semua yang ada pada populasi, misalnya karena keterbatasan dana, tenaga dan waktu, maka peneliti dapat menggunakan sampel yang diambil dari populasi. Sampel yang diambil dari populasi harus betul-betul representif (mewakili). Dikarenakan penelitian ini dilakukan untuk mengetahui apa yang ada di perusahaan daerah air minum (PDAM) lamongan, Sampel yang diambil oleh peneliti yaitu ke efektifan pengelolaan tarif pada perusahaan daerah air minum (PDAM) Lamongan (3) Teknik Sampling

Metode pengambilan sampel yang digunakan adalah Random sampling. Menurut Sugiyono (2013:120). "pengambilan anggota sampel dari populasi dilakukan secara acak tanpa memperhatikan strata yang ada dalam populasi itu".

Berdasarkan uraian diatas maka disini peneliti menggunakan teknik random sampling (pengambilan sample secara acak). Artinya dalam pengambilan sampelnya, peneliti mencampur subyek - subyek didalam populasi sehingga semua subyek dianggap homogen

Jenis Data (1)Data Primer yaitu data yang diperoleh langsung dari obyek penelitian, data tersebut diperoleh dengan cara wawancara langsung ke lapangan dimana datanya masih utuh dan belum dikelola, baik dalam bentuk informasi maupun dalam bentuk angka. Dalam penelitian ini data primer diperoleh dari hasil wawancara kepada bagaian instansi PDAM (Perusahaan
Daerah Air Minum) lamongan tentang analisis penyesuaian tarif dasar pada perusahaan daerah air minum. (b) Data Sekunder Yaitu data yang diperoleh secara langsung dari obyek penelitian berupa data-data yang terkumpul dari dokumen-dokumen perusahaan dan literatur-literatur yang terkait dengan obyek penelitian. Dalam penelitian ini data sekunder yang diperoleh yaitu data tentang gambaran umum PDAM Lamongan.

Teknik Pengumpulan Data Pengumpulan data dalam penelitian ini adalah dengan menggunakan metode sebagai (1) Studi Lapangan Yaitu mengumpulkan data dengan jalan langsung terjun (survei) pada perusahaan yang menjadi objek-objek penelitian, untuk memperoleh data primer dari perusahaan, maka cara yang dilakukan dengan (a) Wawancara yaitu penelitian dengan cara tanya jawab dengan pejabat yang bersangkutan dengan masalah yang diteliti, sehingga peneliti dapat memperoleh data mengenai sejarah dan pengembangan perusahaan, struktur organisasi sifat wawancara yang dilakukan adalah informasi. Sugiono (2012:195). (b) Documenter Yaitu metode pengambilan data dengan cara mempelajari dokumen-dokumen yang ada dan melaksanakan pencatatan dan yang tersedia pada perusahaan daerah air minum (PDAM). (c) Observasi atau disebut dengan pengamatan adalah meliputi kegiatan pemuatan perhatian terhadap suatu obyek dalam menggunakan seluruh alat indra.

Adapun definisi operasional variabel dalam penelitian ini adalah menggunakan variabel: Harga Pokok Penjualan (HPP), Harga Pokok Penjualan menurut Mulyadi (2014: 22), dalam buku yang berjudul akuntansi 
biaya adalah harga pokok yang dikenakan pada suatu barang akibat dari proses penjualan.

$$
\text { Harga Pokok }=\frac{\text { biaya total }}{\text { jumlah air yang dijual }}
$$

Biaya total (Total Cost/TC) Biaya total Menurut Sukirno (2013: 43), merupakan jumlah keseluruhan biaya produksi yang dikeluarkan perusahaan yang terdiri dari biaya tetap dan biaya variabel. Biaya Tetap $\mathrm{TC}=$ $\mathrm{FC}+\mathrm{VC}$

Dalam melakukan penelitian ini metode analisis data yang digunakan adalah: Full Cost Recovery Menurut Kieso (2011:18) adalah Metode pemulihan biaya secara penuh (cost recovery method). Harga Pokok Penjualan (HPP), Harga Pokok Penjualan menurut Mulyadi (2014: 22) dalam buku yang berjudul akuntansi biaya adalah harga pokok yang dikenakan pada suatu barang akibat dari proses produksi.

$$
\begin{aligned}
& \mathrm{BT}= \\
& \mathrm{HPP}=
\end{aligned} \frac{\mathrm{BL}+\mathrm{BTL}}{\mathrm{BT}}
$$

Biaya total (Total Cost/TC) Biaya total Menurut Sukirno (2013: 43), merupakan jumlah keseluruhan biaya produksi yang dikeluarkan perusahaan yang terdiri dari biaya tetap dan biaya variabel. Biaya total dapat dihitung dengan menggunakan rumus sebagai berikut : $\mathrm{TC}=\mathrm{FC}+\mathrm{VC}$ Dimana

$\mathrm{FC}=$ Fix Cost.

$\mathrm{VC}=$ Variabel Cost.

\section{HASIL}

Tabel 1

\begin{tabular}{|c|c|c|c|}
\hline No & Tahun & $\begin{array}{c}\text { Tarif } \\
\text { Dasar } \\
(\mathrm{Rp})\end{array}$ & $\begin{array}{c}\text { Prosentase } \\
\text { Kenaikan }\end{array}$ \\
\hline 1 & 2012 & 2.332 & $7,20 \%$ \\
\hline 2 & 2013 & 2.500 & $42,04 \%$ \\
\hline 3 & 2014 & 2.500 & - \\
\hline
\end{tabular}

Kenaikan Tarif Dasar Tahun 2012

sampai dengan 2014

Penyesuaian Tarif PDAM Kabupaten Lamongan 2014 dan Konsistensi Terhadap Peraturan Menteri Dalam Negeri Nomor 23 Tahun 2006 Perhitungan penyesuaian tarif PDAM Kabupaten Lamongan tahun 2013 berdasar pada Peraturan Menteri Dalam Negeri nomor 23 Tahun 2006 tentang pedoman teknis dan tata cara pengaturan air minum pada perusahaan daerah air minum pada pasal 14 yang menyatakan bahwa untuk perhitungan dan proyeksi biaya dijadikan acuan dalam penetapan tarif. Sesuai dengan peraturan tersebut, maka PDAM Kabupaten Lamongan melaksanakan perhitungan proyeksi biaya dasar, biaya usaha, dan volume air terproduksi yang digunakan sebagai dasar perhitungan tarif air minum.

\section{Tabel 2}

\section{Perhitungan Tarif dasar untuk} kenaikan tarif Tahun 2012-2013

\begin{tabular}{|c|c|c|c|c|}
\hline $\begin{array}{c}\mathrm{N} \\
\mathrm{o}\end{array}$ & \multicolumn{1}{|c|}{ Uraian } & Sat & 2012 & 2013 \\
\hline 1 & $\begin{array}{l}\text { Historis/proy } \\
\text { eksi volume } \\
\text { produksi }\end{array}$ & $\mathrm{M}^{3}$ & $\begin{array}{l}4.965 .22 \\
5\end{array}$ & 5.076 .000 \\
\hline 2 & $\begin{array}{l}\text { Historis/proy } \\
\text { eksi volume } \\
\text { produksi } \\
\text { standar } \\
\text { kehilangan } \\
\text { air (Vol. } \\
\text { produksi }\end{array}$ & $\mathrm{M}^{3}$ & 3.972 .18 & 4.060 .800 \\
\hline
\end{tabular}




\begin{tabular}{|c|c|c|c|c|}
\hline & $80 \%)$ & & & \\
\hline 3 & $\begin{array}{l}\text { Biaya usaha } \\
\text { diluar biaya } \\
\text { bunga dan } \\
\text { depresiasi }\end{array}$ & $\mathrm{Rp}$ & $\begin{array}{l}8.883 .23 \\
6.552,42\end{array}$ & $\begin{array}{l}9.505 .063 . \\
111,09\end{array}$ \\
\hline 4 & $\begin{array}{l}\text { Historis/proy } \\
\text { eksi bunga } \\
\text { pinjaman dan } \\
\text { denda }\end{array}$ & $\mathrm{Rp}$ & $\begin{array}{l}534.172 . \\
792,88\end{array}$ & $\begin{array}{l}851.442 .2 \\
35,26\end{array}$ \\
\hline 5 & $\begin{array}{l}\text { Historis/proy } \\
\text { eksi } \\
\text { pembayaran } \\
\text { pinjaman } \\
\text { (pokok)/Depr } \\
\text { esiasi }\end{array}$ & $\mathrm{Rp}$ & $\begin{array}{l}1.882 .34 \\
0.663,43\end{array}$ & $\begin{array}{l}1.978 .518 \\
857,10\end{array}$ \\
\hline 6 & $\begin{array}{l}\text { Historis/Proy } \\
\text { eksi total } \\
\text { biaya } \\
\text { usaha(biaya } \\
\text { bunga dan } \\
\text { depresiasi + } \\
\text { bunga } \\
\text { pinjaman dan } \\
\text { denda + } \\
\text { pembayaran } \\
\text { pinjaman) }\end{array}$ & $\mathrm{Rp}$ & $\begin{array}{l}11.299 .7 \\
49.978,7 \\
3\end{array}$ & $\begin{array}{l}12.335 .02 \\
4.203,45\end{array}$ \\
\hline 7 & $\begin{array}{l}\text { Proyeksi } \\
\text { Tarif Dasar } \\
\text { (Total biaya } \\
\text { usaha/ vol. } \\
\text { produksi - } \\
\text { standar } \\
\text { kehilangan } \\
\text { air }\end{array}$ & $\mathrm{Rp}$ & $2.884,72$ & $3.037,58$ \\
\hline 8 & $\begin{array}{l}\text { Kebijakan } \\
\text { Tarif dasar } \\
2012-2013 \\
(\text { Tarif dasar x } \\
82 \%)\end{array}$ & $\mathrm{Rp}$ & 2.332 & 2.490 \\
\hline
\end{tabular}

Sumber : Data Diolah

Dari tabel 5.4 dalam pembahasan penyesuaian tarif PDAM Kabupaten Lamongan tarif dasar (TD) yang dihitung dari proyeksi biaya usaha dan proyeksi volume produksi air dinilai terlalu tinggi, sehingga disepakati kebijakan kenaikan tarif dasar untuk tahun 2013 hanya sebesar $82 \%$ dari proyeksi tarif dasar yang diperhitungkan. Kebijakan tarif dasar tahun 2013 sebesar $82 \%$ dari proyeksi tarif dasar adalah sebesar Rp2.490 yang dibulatkan menjadi Rp2.500.

Dari tarif ini yang telah diketahui tersebut selanjutnya dilakukan perhitungan tarif rendah dan tarif penuh dengan rumusan sebagai berikut:

Tarif Rendah (TR) $=75 \% \quad \mathrm{X}$ tarif dasar

Rp1.870

$$
=75 \% \times 2.490=
$$

Tarif Penuh $(\mathrm{TP}) \quad=200 \% \mathrm{X}$ tarif dasar

$=4.970$

$$
=200 \% \times 2.490
$$

Metode full costing sejalan dengan Peraturan Mentri Dalam Negeri nomor 23 Tahun 2006 tentang pedoman teknis dan tata cara pengaturan air minum pada perusahaan daerah air minum pada pasal 5 ayat (1) menyatakan bahwa pendapatan PDAM harus memenuhi prinsip pemulihan biaya. Pemulihan biaya secara penuh (full cost recovery) dicapai dari hasil perhitungan tarif rata-rata minimal sama dengan biaya dasar. Biaya dasar merupakan pembagian antara biaya usaha (seluruh total biaya untuk menghasilkan air minum yang mencangkup biaya sumber air, biaya pengolahan air, biaya transmisi dan distribusi, biaya kemitraan, dan biaya umum dan standar. Dengan demikian metode full costing diadopsi dan dikenal dengan istilah full cost recovery dalam PDAM.

Harga pokok produksi air menggunakan metode full costing dirumuskan sebagai berikut : $\mathrm{HPP}=$ Biaya Usaha dibagi volume produksi dikurangi kehilangan air standart .

Rumus:

HPP

Biaya Usaha

Vol Pro-Kehilangan Air Standar (20\% dari Vol Pro) 
1. Tahun 2012 :

$$
\frac{10.983 .396 .153}{4.965 .225-993045}=2.765
$$

2. Tahun 2013 :

$$
\frac{12.778 .431 .635}{5.379 .183-1.075 .837}=2.969
$$

3. Tahun 2014 :

$$
\frac{15.570 .178 .874}{5.280 .769-1.158 .629}=3.777
$$

Dari perhitungan harga pokok air tersebut maka dapat diketahui bahwa HPP air per $\mathrm{M}^{3}$ Pada PDAM Kabupaten Lamogan pada tahun 2012 ke tahun 2014 HPP air mengalami kenaikan menjadi sebesar Rp 3.777 karena terjadi kenaikan total biaya produksi yang diikuti volume produksi.

\section{KESIMPULAN DAN SARAN Kesimpulan}

Berdasarkan hasil penelitian dan pembahasan pada bab sebelumnya, maka dapat disimpulkan bahwa Dalam melaksanakan penyesuaian tarif air. PDAM Kabupaten Lamongan secara umum telah melaksanakan sesuai dengan Peraturan Menteri Dalam Negeri nomor 23 Tahun 2006, dengan adanya penyesuaian tarif air tersebut pada tahun 2014 tarif dasar tidak mengalami kenaikan (Tetap) sebesar $2.500 \mathrm{M}^{3}$.

Untuk menentukan cara harga pokok produksi Perusahaan Daerah Air Minum (PDAM) Lamongan menggunakan Metode penentuan HPP dengan pendekatan full costing menggunakan komponen biaya antara lain bahan baku, biaya tenagakerja, biaya overhead baik tetap maupun variabel dan biaya umum dan adminitrasi, dengan hasil perhitungan HPP pada tahun 2012 sebesar : 2.765, tahun 2013 sebesar : 2.969, tahun 2014 sebesar : 3.777 , sehinggan perusahaan mengalami kerugian pada HPP Harga pokok produksi.

\section{Saran}

Arah pengelolaan pendapatan daerah di masa mendatang difokuskan sebagai berikut: Dalam melakukan proses kenaikan tarif sebaiknya PDAM Kabupaten Lamongan juga menyelenggarakan kajian tentang dampak kenaikan beban per bulan kepada kelompok-kelompok pelanggan. Hal ini belum dilakukan PDAM Kabupaten Lamongan dalam proses penyesuaian tarif air minum tahun 2013-2014. Diharapkan PDAM Kabupaten Lamongan dapat meningkatkan kinerja perusahaan terutama dalam hal penurunan kehilangan air Non Revenue Water (NRW) distribusi, dimana tingkat kehilangan air pada tahun 2013 mencapai $32 \%$ dari volume produksi.

\section{DAFTAR PUSTAKA}

Danang Sunyoto,.Dasar-dasar Manajemen Pemasaran. Penerbit CAPS, Yogyakarta 2012.

Sukirno, Sudino. Teori Pengantar Ekonomi Mikro. Edisi Ketiga, Jakarta : PT. Raja Grafindo persada 2013

Wilson Bangun, 2014. Teori Ekonomi Mikro penerbit PT Revika Aditama. Bandung 2014: 40254

Irham Fahmi. Manajemen Produksi dan Oprasi, Penerbit Alfabeta. Bandung 2012

Arikunto, Suharsimi. Prosedur Penelitian. Edisi Revisi. Jakarta PT.Rineka Cipta 2010

Sugiyono.Metode Penelitian Kuantitatif, Kualitatif, R \& D. Bandung, AlfaBeta 2014 